\title{
EBSD study of Quartz $c$-axis orientations in the silicified host rocks of the Kasuga gold deposit, Southwest Japan
}

\author{
Tayyaba Mateen, Hafiz Ur Rehman and Hiroshi Yamamoto \\ Department of Earth and Environmental Sciences, Graduate School of Science and Engineering, \\ Kagoshima University, 1-21-35 Korimoto, Kagoshima 890-0065, Japan
}

\begin{abstract}
The Kasuga High Sulfidation gold deposit is hosted in the silicified Late Miocene andesite of Nansatsu Volcanic Rocks in the southern part of the Satsuma Peninsula, Southwest Japan. Optical microscopic observations and X-ray fluorescence spectrometry (Horiba XGT-5000) analysis of two silicified andesite samples from the Kasuga ore body revealed that the rocks underwent different degrees of hydrothermal alteration and no tectonic deformation afterward. Crystallographic orientations of quartz composing the silicified andesite samples studied using Electron Backscatter Diffraction, EBSD (EDAX GE-1, TSL-OIM) displayed different trends in the $c^{-a x-}$ is orientations between the samples. The $\boldsymbol{c}$-axes of quartz grains are mainly oriented sub-horizontal or plunging at low angles in the less-silicified andesite. The highly silicified sample has larger quartz grains with $\boldsymbol{c}$-axes plunging at high angles. The difference in $\boldsymbol{c}$-axis orientations is provably related to the silicification processes in the earlier and later stages of hydrothermal alteration. The results of this study suggest that quartz $c$-axis orientations of rocks deformed under low strain regimes are potentially inherited from initial undeformed state, for example crystallization from hydrothermal solutions.
\end{abstract}

Keywords: Silicification, Hydrothermal, Tectonic deformation, $\boldsymbol{c}$-axis orientations, Electron Backscatter Diffraction

\section{INTRODUCTION}

Crystallographic fabrics of the major rock-forming minerals tell us the rheology and deformation mechanism of the crust and upper mantle. Quartz is the main target mineral of fabric analysis for felsic rocks because of its ubiquity and relative stability under crustal conditions. The optical measurement of quartz $\boldsymbol{c}$-axis fabric needs welltrained technique and patience of a researcher. It was a large obstacle to study the rheology and deformation mechanism of quartz for many years. Electron backscatter diffraction (EBSD) analysis has brought technological innovation in the study of crystallographic fabrics (e.g., Prior et al., 1999, 2002; Gonçalves and Lagoeiro, 2009). A computer assisted EBSD analysis system can determine complete crystallographic orientations of an appreciable number of grains within a short span of time. The EBSD analysis of quartz is generally aimed at intensely deformed mylonitic rocks. There is a growing number of

doi:10.2465/jmps.130118b

T. Mateen, k9977115@kadai.jp Corresponding author

H.U. Rehman, hafiz@sci.kagoshima-u.ac.jp

H. Yamamoto,hyam@sci.kagoshima-u.ac.jp publications including the results of quartz fabric analysis and most of them deal with the use of $\boldsymbol{c}$-axis fabric in interpreting the processes related to deformation, for example dynamic recrystallization (Vernooij et al., 2006; Trepmann et al., 2010), and solution-precipitation (Den Brok and Spiers, 1991; Hippertt, 1994) etc. Quartz crystallographic fabric of deformed rocks attracts the interest of many researchers however, the initial state of crystallographic orientations before deformation has not been well investigated.

This paper presents quartz crystallographic fabrics of silicified rocks taken from the ore body of Kasuga gold deposit in southern Kyushu formed by the silicification of Pliocene andesite (Urashima et al., 1987; Hedenquist et al., 1994). Neither the ore body nor the protolith andesite has undergone any tectonic deformation. Detailed analysis of undeformed rocks will contribute to the comprehensive understanding of quartz fabric from initial to intensive deformation stages.

\section{GEOLOGICAL SETTING}

Kyushu is the third largest Japanese island with an area of 


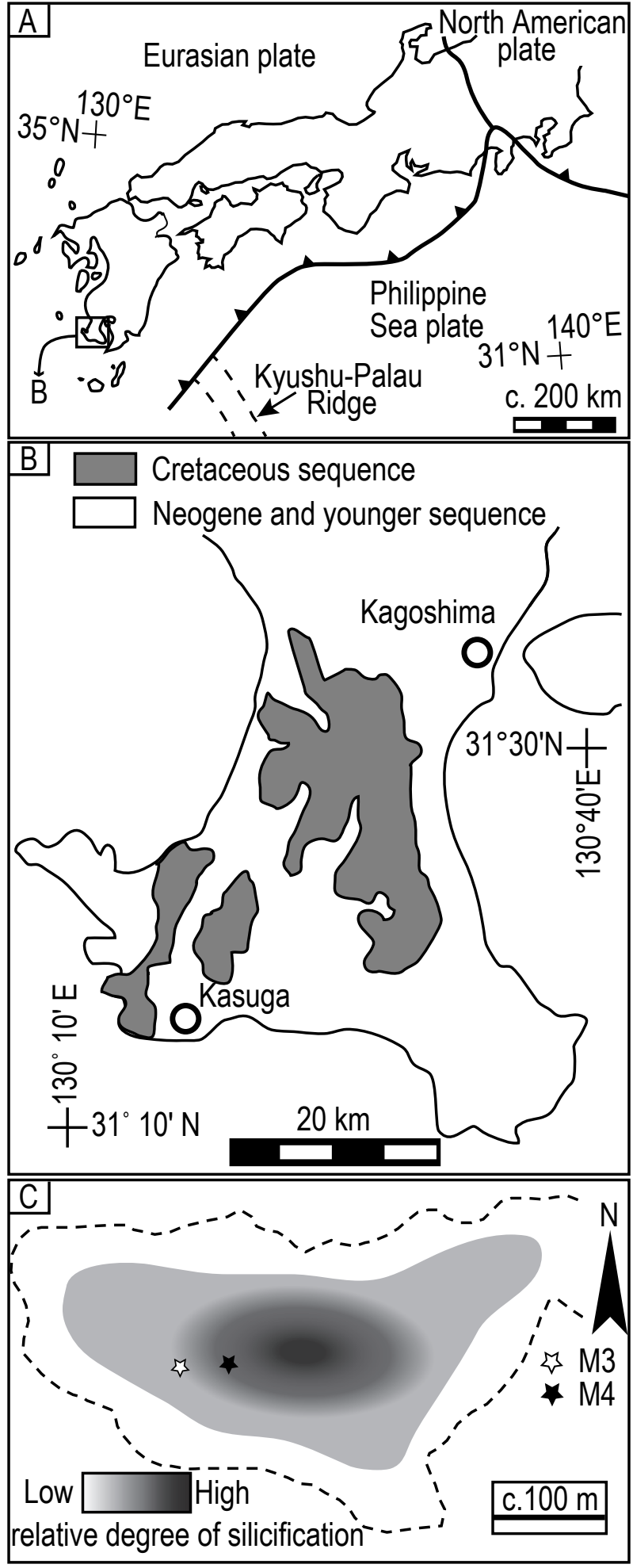

Figure 1. (A) Geological setting of Kyushu with respect to the Japanese islands and the underlying tectonic plates (study area boxed). (B) Enlarged view of the boxed area in (A) showing location of the Kasuga mine. (C) Sketch indicating sample locations in the opencast of Kasuga gold deposit. Zones of different degrees of silicification are drawn based on descriptions in Hedenquist et al. (1994) and Takeda et al. (2001). nearly 36000 square kilometers located at the junction of two island arcs: the Southwest Japan arc and the North Ryukyu arc (Kodama et al., 1995). Basement of the southern Kyushu is comprised of Shimanto Supergroup, the Upper Cretaceous to Neogene accretionary prism. Southern part of the Satsuma Peninsula (Fig. 1A) is called the Nansatsu area. Main geological components of the Nansatsu area are Saiki Subgroup (Upper Cretaceous sandstone, mudstone, and minor basaltic rocks), Kawanabe Group (Upper Cretaceous sandstone and mudstone), Middle Miocene granitic intrusive rocks, Late MiocenePliocene Nansatsu Voclanic Rocks (volcanic rocks and volcaniclastic sediments), and Plio-Pleistocene volcanic rocks with volcaniclastic sediments (Uto et al., 1997; Kawanabe et al., 2004). Several gold deposits (Akeshi, Iwato, Kasuga, etc.) are distributed in the Nansatsu area. These are classified as 'Nansatsu-type' epithermal gold deposits (Urashima, 1975). The gold deposits are tectonically situated above the subducting northern extension of the Kyushu-Palau Ridge (Cooke et al., 2005) (Fig. 1A). Hydrothermal activity in the area which took place at about 4.5 Ma (Takeda et al., 2001) resulted in the interaction of acidic magmatic fluids with meteoric water under epithermal conditions and caused formation of the highsulfidation deposits consisting of approximately $95 \% \mathrm{SiO}_{2}$ (Hedenquist et al., 1994). The sulfidation and silicification of the Late Miocene andesite of the Nansatsu Volcanic Rocks was accompanied by gold mineralization (Urashima, 1975; Izawa and Cunningham, 1989; Hedenquist et al., 1994; Watanabe, 2005).

The Kasuga gold deposit is one of the Nansatsu-type (high-sulfidation) ore bodies near the southwestern end of the Satsuma Peninsula (Fig. 1B). This deposit is composed of mushroom-shaped silicified rock body which is enveloped in a zone of weakly silicified rock (Takeda et al., 2001). This weakly silicified zone grades outward into two-pyroxene andesite. According to a model for gold mineralization in the Nansatsu District, the volcanic host rocks underwent upward- and outward-modification by the ascending fluids from an intrusion at depth (Hedenquist et al., 1994). The ore body extends about $200 \mathrm{~m}$ from north to south and $500 \mathrm{~m}$ from east to west (Fig. $1 \mathrm{C})$, and is approximately $100 \mathrm{~m}$ thick in its central part.

\section{PETROGRAPHY}

Rock samples were collected from the non-silicified andesite from outside of the Kasuga gold deposit and labeled M1 and M2. Two other samples from the ore body were obtained: M3 from the relatively less silicified zone and M4 from a considerably silicified portion (Fig. 1C and Figs. 2A and 2B). Described below are the petro- 

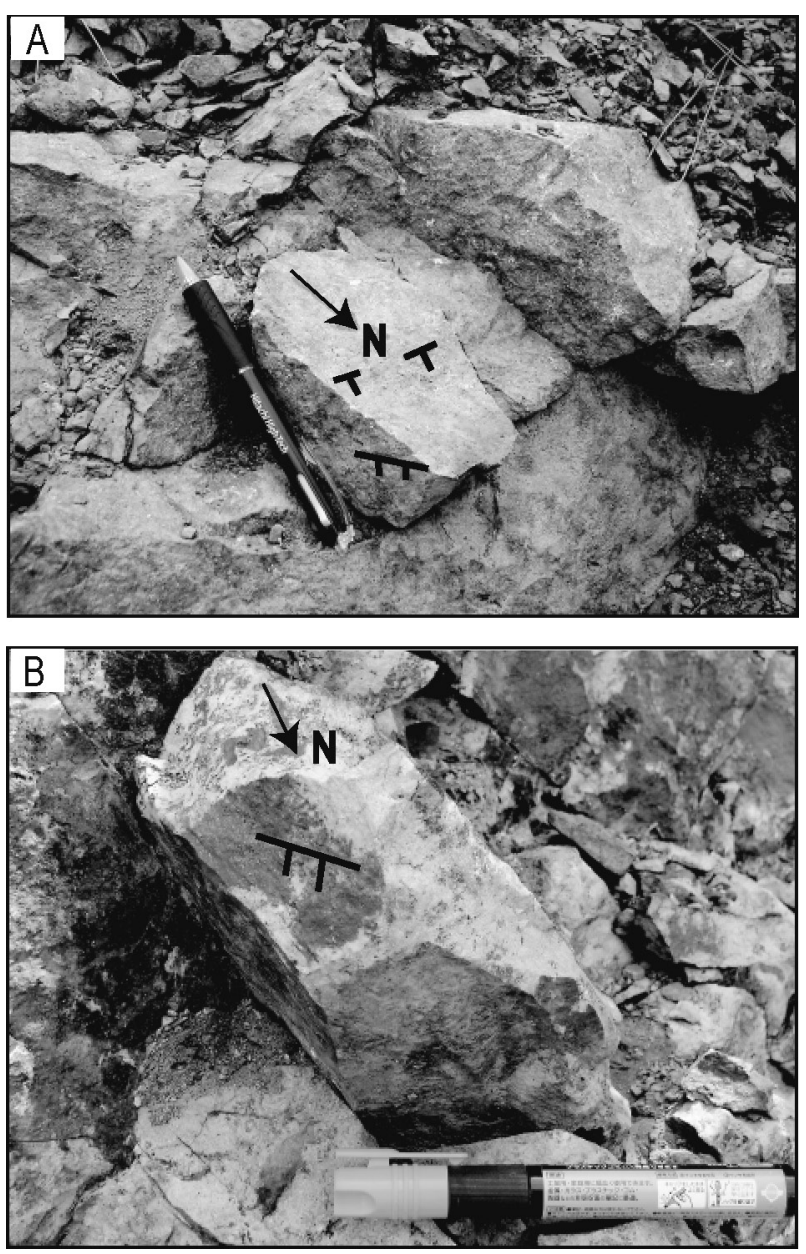

Figure 2. Oriented silicified rock samples at the outcrop. The Tshaped marks represent the horizontal. The arrowhead points North. (A) M3 in the less-silicified rock. (B) M4 in the highlysilicified rock.

graphic details of each rock type.

\section{Andesite}

M1 $\left(31^{\circ} 15^{\prime} 19.5^{\prime \prime} \mathrm{N}\right.$ and $\left.130^{\circ} 16^{\prime} 6.6^{\prime \prime} \mathrm{E}\right)$ and M2 $\left(31^{\circ} 15^{\prime} 19.5^{\prime \prime} \mathrm{N}\right.$ and $\left.130^{\circ} 16^{\prime} 9.1^{\prime \prime} \mathrm{E}\right)$ are dark gray to black in colour and porphyritic (medium to fine-grained). Major constituent minerals are plagioclase, orthopyroxene, augite and hornblende with accessory ilmenite, magnetite and epidote. Phenocrysts of plagioclase are albite-Carlsbad twinned (Fig. 3A), oscillatory zoned and include rutile and apatite. Plagioclase phenocrysts are generally altered to sericite, clay minerals and epidote in their core part. Phenocrysts of pyroxene are also common (Fig. 3B). Orthopyroxene is more abundant than augite. They contain inclusions of rutile and opaque minerals. Groundmass is mainly composed of fine-grained plagioclase and glassy material. No signature indicating the effect of any tectonic deformation is recognizable in these andesite
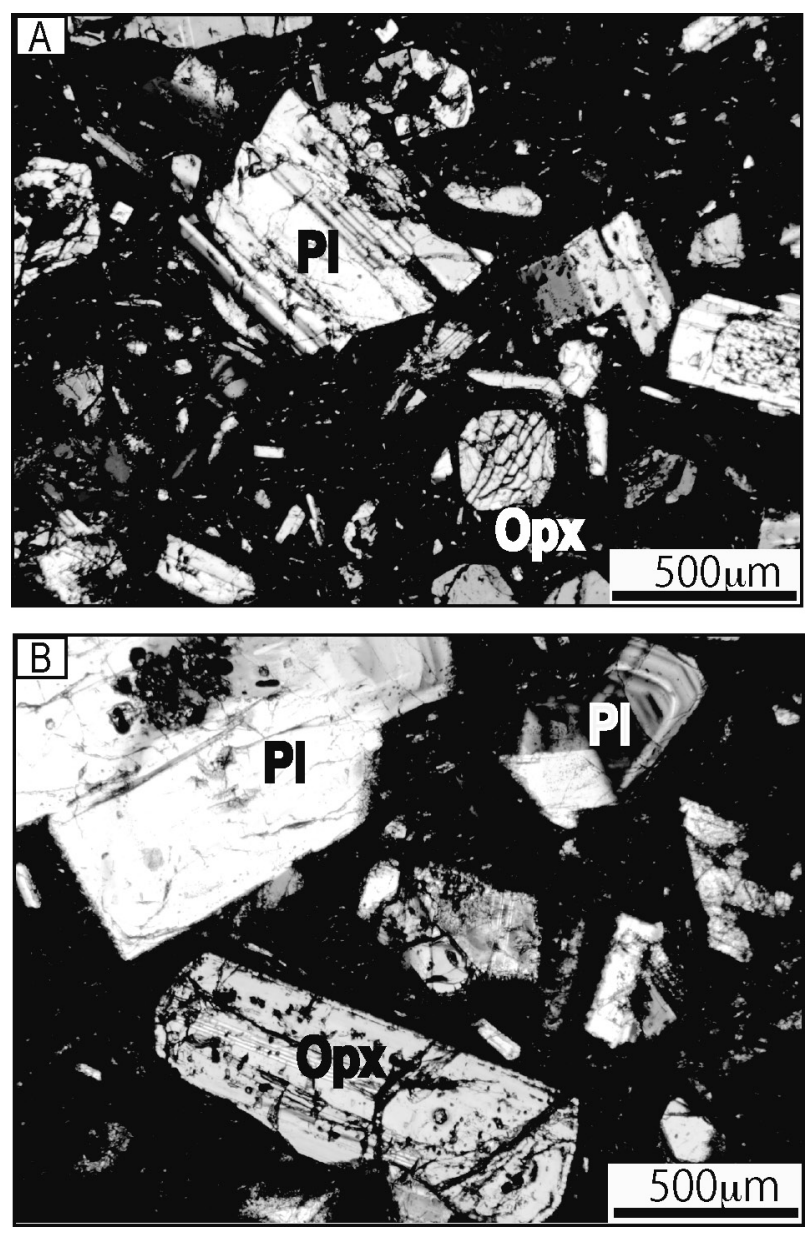

Figure 3. Photomicrographs of andesite. (A) M1 with twinned plagioclase $(\mathrm{Pl})$ and orthopyroxene (Opx) in a glassy groundmass. (B) M2 with oscillatory zoned plagioclase and inclusions in both orthopyroxene and plagioclase.

samples.

\section{Silicified rocks}

Sample M3 $\left(31^{\circ} 16^{\prime} 10^{\prime \prime} \mathrm{N}\right.$ and $\left.130^{\circ} 15^{\prime} 23.5^{\prime \prime} \mathrm{E}\right)$ is light gray silicified andesite. The rock has abundant voids and contains opaque minerals including pyrite and magnetite with the main composition being quartz $(>95 \%)$. The voids (Fig. 4A) are formed by the dissolution of igneous minerals in the protolith andesite consisting of pyroxenes and plagioclase. Almost all the quartz is anhedral and large pyrite cubes can be spotted easily under reflected light (Fig. 4B). Euhedral crystals of quartz (larger quartz grains with straight grain boundaries) can be seen penetrating into the dissolution voids (Fig. 4C).

Sample M4 $\left(31^{\circ} 16^{\prime} 9.8^{\prime \prime} \mathrm{N}\right.$ and $\left.130^{\circ} 15^{\prime} 25.2^{\prime \prime} \mathrm{E}\right)$ is relatively more silicified andesite. The rock is much harder than M3 and has no voids visible to the naked eye. Presence of rusting iron oxides (or hydroxides) gives a reddish 

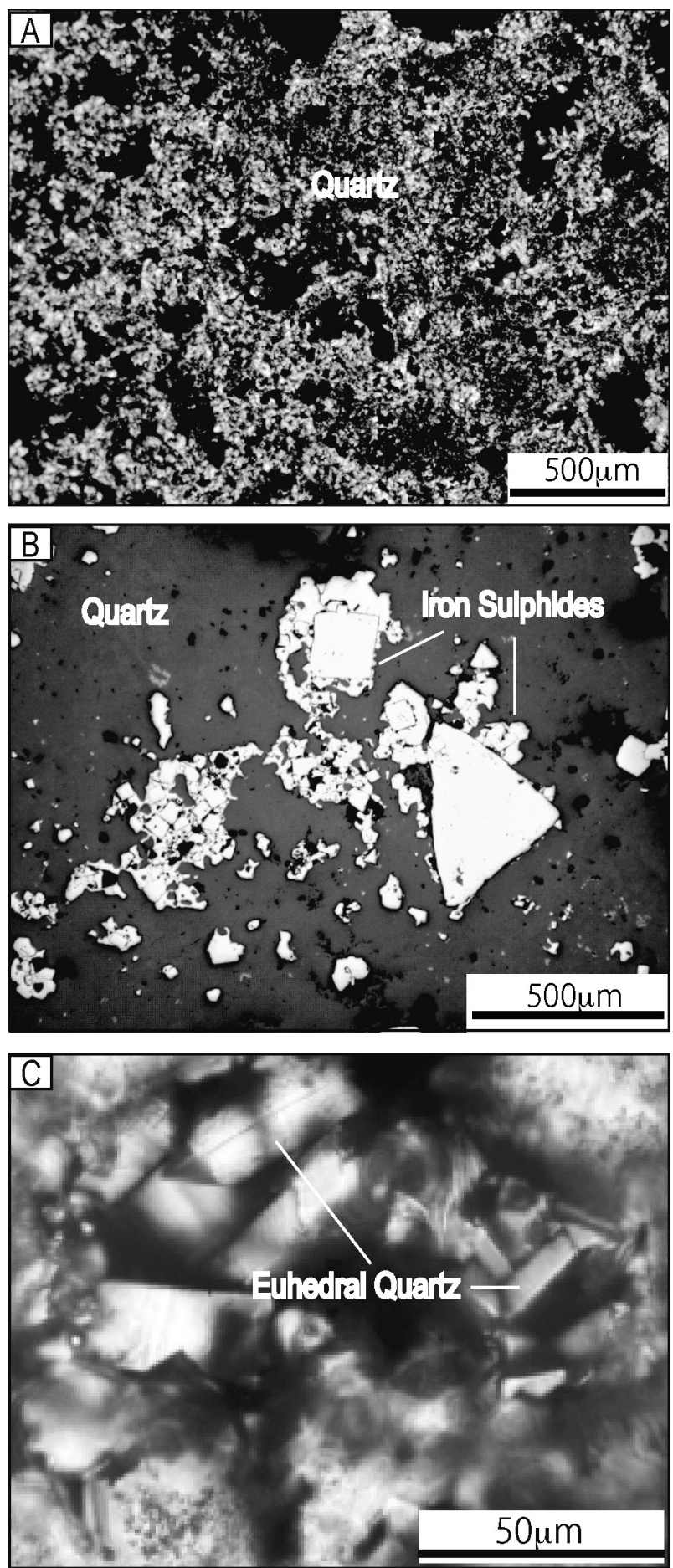

Figure 4. Photomicrographs of M3. (A) Quartz-dominated sample under cross-polarized light. Voids appear in black. (B) Reflected light image showing iron sulphides in regular and irregular shapes saturated at one location. (C) Large quartz grains with straight grain boundaries lining the voids.

appearance to the white quartz-rich rock. Two types of quartz grain-sizes are identified in the thin section. Coarser quartz grains form an inequigranular mosaic with finegrained quartz (Fig. 5A). Euhedral quartz is visible at
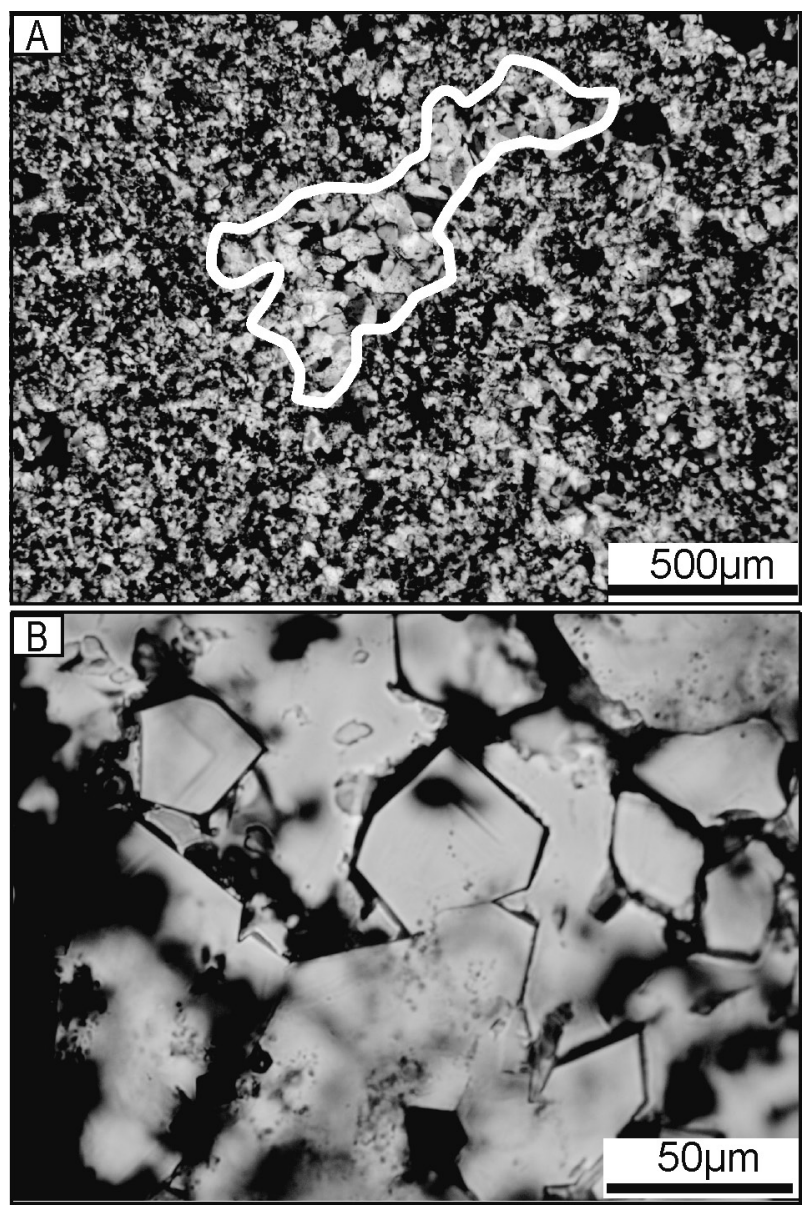

Figure 5. Photomicrogaphs of M4. (A) Mosaic of fine- and coarsegrained quartz under crossed polarized light (coarser grains enveloped by a thick white line). (B) Euhedral quartz grains visible under plane polarized light.

high magnification (Fig. 5B).

\section{SAMPLE PREPARATION FOR EBSD ANALYSIS AND ANALYTICAL WORK}

Oriented samples M3 and M4 were cut into rectangular blocks to obtain the North-aligned horizontal surface. Cylindrical cores $(2.1 \mathrm{~cm}$ in diameter and $4 \mathrm{~cm}$ height, with North direction marked on the top) were picked from the blocks using a core picker (Fig. 6). The bottom surfaces of the cores were polished and mounted onto circular glass slides $(\varphi 25)$ using epoxy resin and recut into thin sections $(\sim 30 \mu \mathrm{m}$ thickness). North direction was also marked on the glass slide to find its orientation in the SEM. The thin sections were then polished using grinders of various grit sizes, $1 \mu \mathrm{m}$ diamond paste, $0.3 \mu \mathrm{m}$ alumina suspension, and washed in an ultrasonic bath for 15 to 20 min. Standard optical microscopy and X-ray Guide Tube system (Horiba XGT-5000) were used to assess the mineralogy of each sample prior to chemical polish using 20 


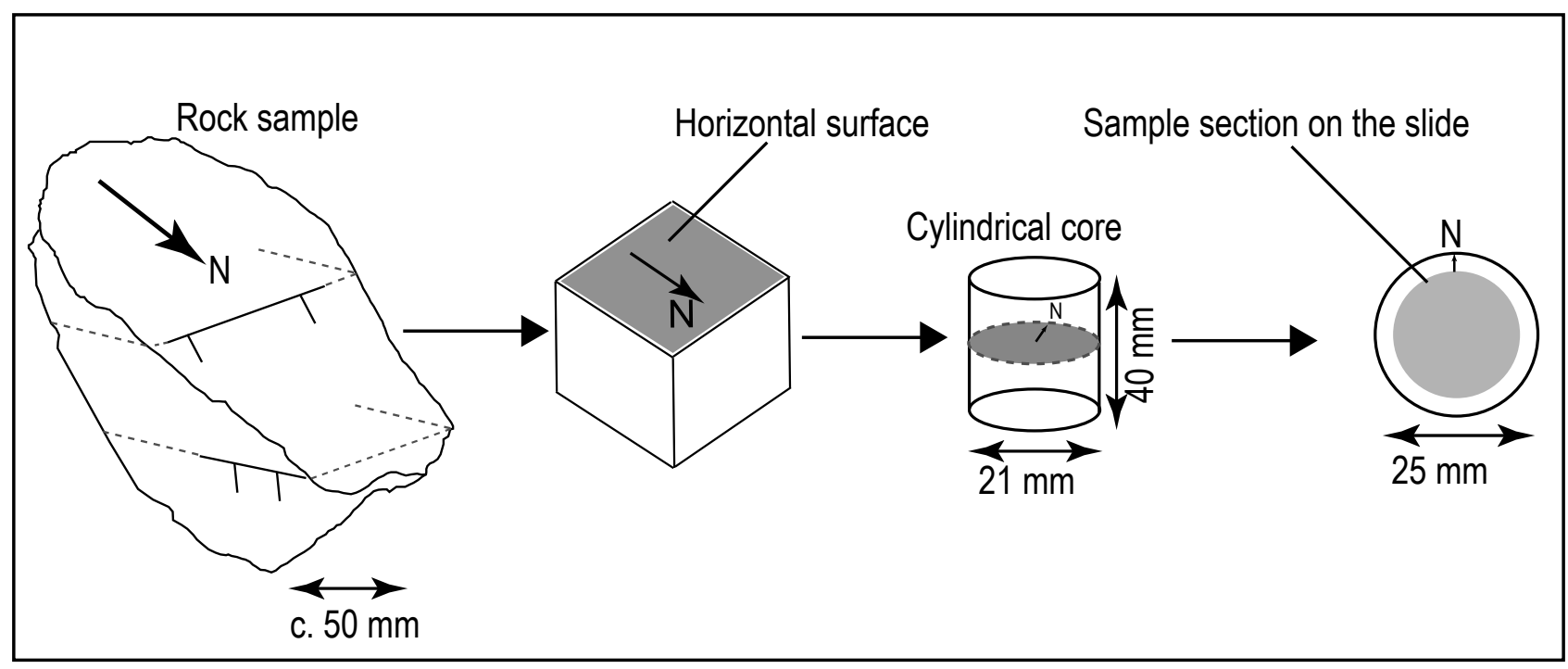

Figure 6. Illustration of the steps involved in obtaining the North-oriented thin section from the rock samples.
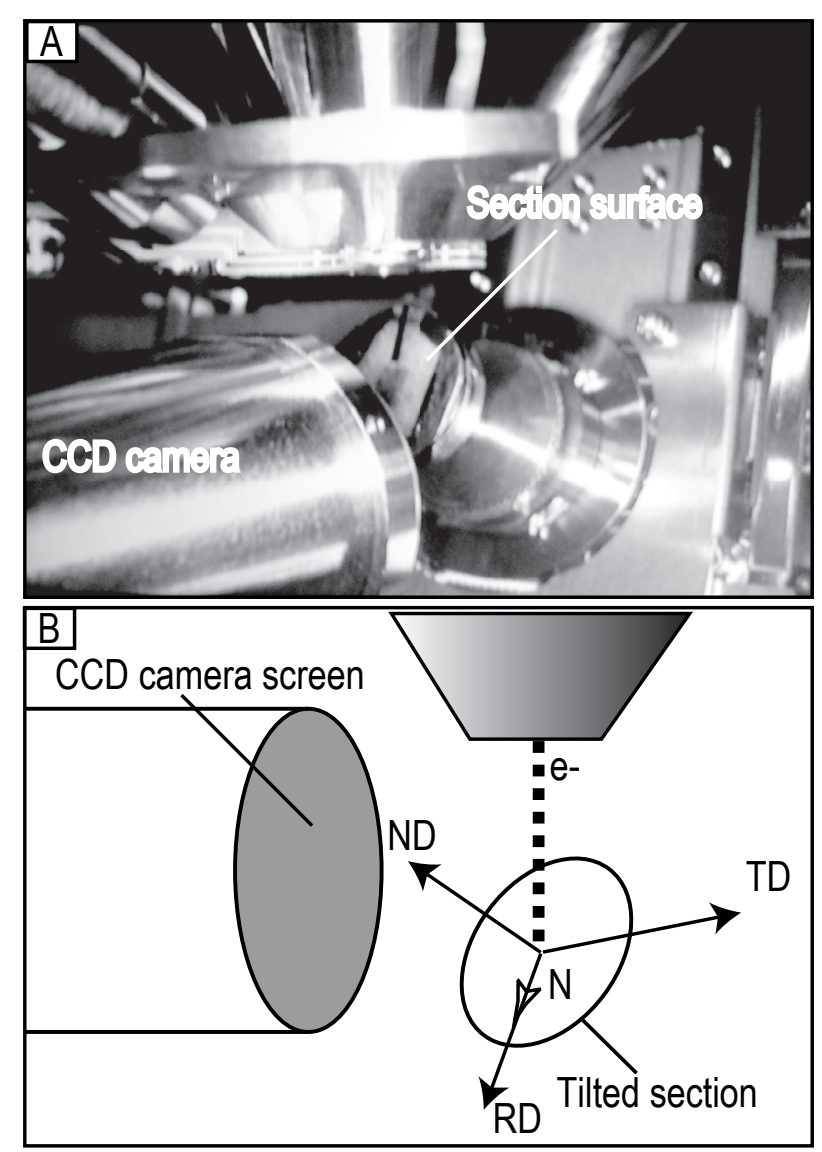

Figure 7. (A) Picture from inside the SEM SU-70 chamber showing the tilted sample in front of the CCD camera. (B) Illustration of the sample position with respect to the default reference frame of the EBSD analysis system of the SU-70 (ND: Normal Direction, RD: Rolling Direction, TD: Transverse Direction, e': electron beam). $\mathrm{nm}$ colloidal silica gel $(\sim 2 \mathrm{~h})$ for EBSD analysis. Surfaces of samples appeared flat under the reflected light microscope. In order to make the surfaces of the thin sections free of any dirt or impurities, FEMTO SCIENCE CUTE$\mathrm{MP} / \mathrm{R}$ table top low vacuum plasma cleaning system was used for 1 min per section and then a conductive (carbon $<20 \mathrm{~nm}$ ) coating was applied.

The scanning electron microscope Hitachi SEM SU70 and EDAX GE-1 EBSD Detector with TSL-OIM Data Collection Software 5.3 at the Division for Instrumental Analysis, Natural Science Center for Research and Education, Kagoshima University was used to collect the quartz orientation data. Operating parameters during EBSD data collection included an accelerating voltage of $20 \mathrm{kV}$ and an emission intensity of 31-32 $\mu \mathrm{A}$ of the field emission gun. A working distance of 25-27 mm was maintained. The reference frame of orientation measurement is shown in Figure 7 where RD (rolling direction) corresponds to the North mark on the section surface. Data acquisition parameters were high gain, a binned pattern size of 160 , a theta step size of $0.5^{\circ}$, and 11 reflector families for trigonal quartz. These parameters combined with medium resolution of the Classic Hough Transform were set for indexing of the diffraction patterns and to prevent the charge-coupled device (CCD) camera from adding false signals to the actual diffracted electrons from the sections, careful background subtraction was done. This setup ensured a maximum confidence index and minimum fit values for automatic scanning and indexing. Before initiating the area scans care was taken to avoid including features such as voids or iron sulphides to prevent erroneous indexing. The grains vary in size between a few microns to tens of microns in the samples and no 
location is distinctly fine-grained or coarse-grained hence the step size value was kept moderate $(1 \mu \mathrm{m})$ to avoid overlooking small grains within the scan area. Multiple scans were carried out at various locations on each section surface.

TSL OIM Analysis Software version 5.2 was used for post-processing of the orientation data. Erroneous pattern indexing was corrected by a clean-up procedure consisting of single iteration grain dilation with the parameters of grain tolerance being $10^{\circ}$ misorientation and a minimum grain size of 5 pixels. Orientation maps and pole figures were plotted from the cleaned and merged data for various scans on the section surface.

\section{RESULTS}

\section{Chemical composition}

The thin sections of silicified andesite were studied using $\mathrm{X}$-ray fluorescence spectrometry (XGT-5000) in order to know the major element ( $\mathrm{Si}, \mathrm{Al}, \mathrm{Fe}, \mathrm{Ca}, \mathrm{Na}, \mathrm{K}, \mathrm{Mg}, \mathrm{P}, \mathrm{S}$, etc.) composition of the main mineral phases. The fully integrated software gave qualitative data as images indicating relative concentration of elements (Fig. 8).

The samples M3 and M4 are roughly similar in chemical composition. Abundance of $\mathrm{Si}$ is almost homogenous throughout the sections. Spots devoid of Si are oc- cupied by $\mathrm{Fe}$ and $\mathrm{S}$ in $\mathrm{M} 3$ confirming the presence of iron sulphides (Fig. 8A). M4 shows no noticeable counts for S. The sporadic high Fe counts (Fig. 8B) are probably due to the iron oxides. A difference in the maximum count for $\mathrm{Si}$ within these samples is due to the low and high levels of silicification in M3 and M4, respectively. Ti occurrence is attributed to rutile or anatase and it is a remnant of the host andesite (Hedenquist et al., 1994). The silicified sections do not have any significant amounts of $\mathrm{K}, \mathrm{Ca}$, and $\mathrm{Al}$, etc. confirming complete leaching out of mineral phases (hornblende, plagioclase, pyroxene, etc.) present in the protolith andesite.

\section{Quartz $c$-axis orientation data}

In naturally deformed rocks, crystallographic preferred orientations (CPO's) of quartz are abundantly used as strain-, strain rate-, vorticity and temperature microgauges for studying deformation history of rocks (Passchier and Trouw, 1996). Since intracrystalline slip due to deformation in quartz is most likely to occur on the (0001) or $\boldsymbol{c}$-plane and also because the $\boldsymbol{c}$-axis can act as unique reference direction with respect to which other three directions $\left(a_{1}, a_{2}, a_{3}\right)$ are crystallographically equivalent, poles to the (0001) plane of quartz can be stereographically projected on a stereonet (pole figure, PF) and contours drawn around the pole populations to indicate the variety
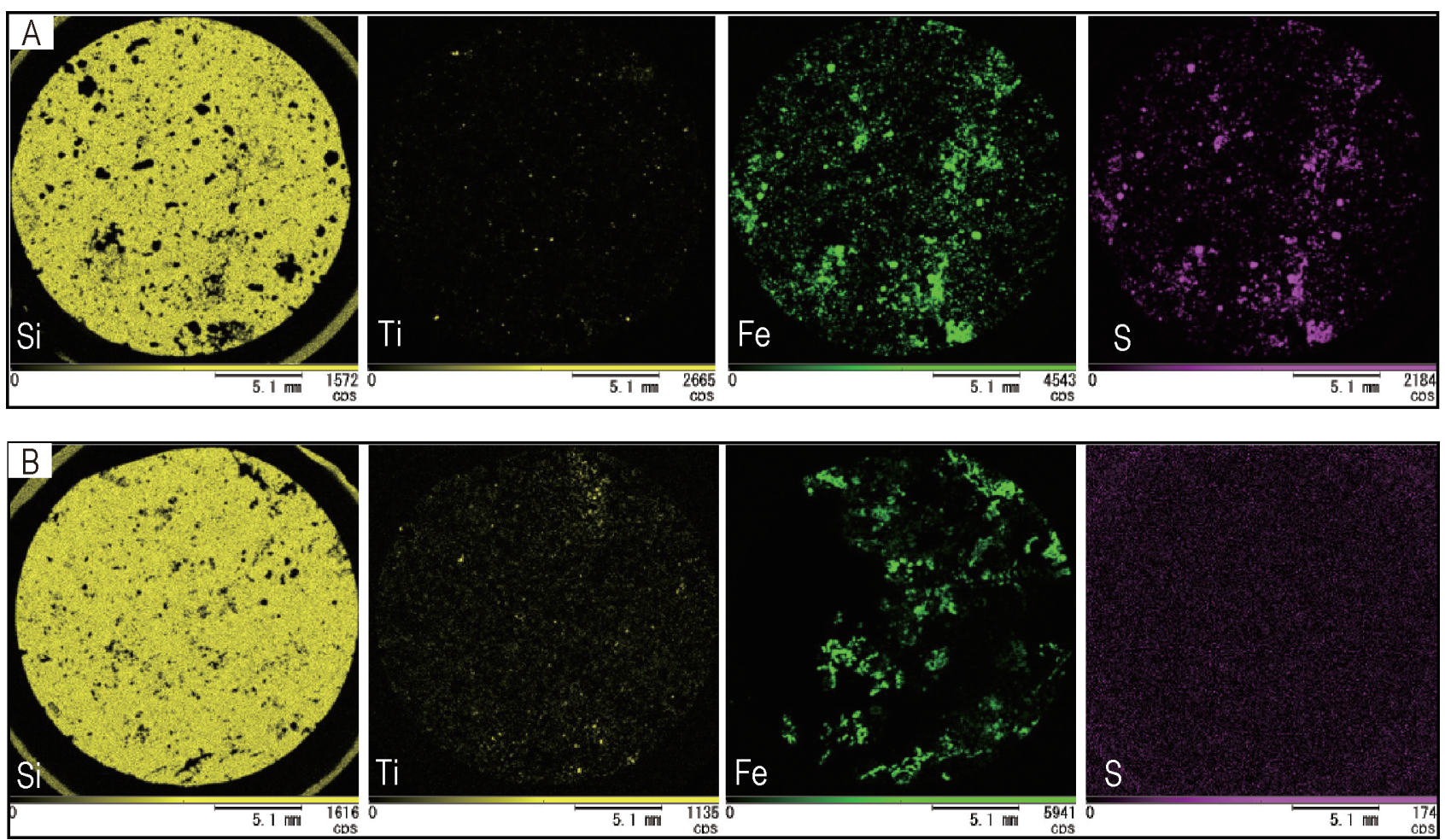

Figure 8. XGT images showing relative elemental concentration of samples. (A) M3. (B) M4. 
of orientations involved with respect to the [0001] direction or $c$-axis. In this study the PF's are shown as intensity plots where the regions of high intensity (near the red end of the colour scale) are associated with the clustering of points in the orientation space. The scale indicates pole densities in multiples of a random distribution. For mylonitic rocks the foliation and lineation are generally used as the known reference directions with respect to which the $\boldsymbol{c}$-axis preferred orientations are studied, however in this study of non-foliated and non-lineated rocks, the horizontal plane and the geographical North are the possible references. The projection framework of these [0001] PF's is similar to the stereonets commonly used for structural geology (lower hemisphere equal-area projection). A directional trend in the distribution of poles in such a figure indicates the preferred direction for quartz crystallization.

According to the OIM Analysis software manual, the image quality (IQ) map is an illustration of the signal intensity captured and subsequently indexed by the system. Regions with light-gray colour on the map record high quality and black areas show unindexed locations (Figs. $9 \mathrm{~A}$ and $9 \mathrm{E}$ ). The quartz grains are distinctly visible in the IQ maps for both M3 (Fig. 9A) and M4 (Fig. 9E) with an average grain size having a larger value in the map from M4. In an inverse pole figure (IPF) map each point is shaded according to the alignment of sample normal direction, ND, relative to the crystal reference frame of quartz. The colour is based on a colour-coded inverse pole figure shown in Figures 9B and 9F. Thus a grain with $\boldsymbol{c}$-axis perpendicular to the sample surface (or a vertical $c$-axis) appears in red. In the IPF map for M3 a majority of grains are coloured close to shades of blue (Fig. 9B) suggesting a trend toward horizontal arrangement of quartz $\boldsymbol{c}$-axis. The [0001] PF's for M3 indicate scattered $c$-axis orientations with most maxima (clustering of poles to $c$-plane) on the periphery of pole figure (Figs. 9C and 9D). Similar [0001] PF's were obtained for multiple scans at different locations on M3. We cannot find any conspicuous preferred alignment from the results however we can conclude that the $\boldsymbol{c}$-axis of the majority of quartz grains in M3 are oriented sub-horizontally or plunging at low angles (Fig. 10A). The IPF map for M4 (Fig. 9F) has more shades of red indicating a dominance of vertically arranged $c$-axes. The [0001] PF's for M4 (Figs. 9G and 9H) show maxima in the center of the figures. The difference between M3 and M4 is found in the concentration of the $c$-axis maxima towards and away from the center of the PF's. The central distribution in M4 pole figures indicates that most of the quartz grains of M4 have their $c$-axis plunging in high angles (Fig. 10B), which are uncommon in case of M3 (Fig. 10A).

\section{DISCUSSION AND CONCLUSION}

M3, sample with a lesser degree of silicification, is dominated by fine-grained, anhedral quartz that formed as a result of replacement of the groundmass (fine-grained plagioclase and glassy matrix) of the protolith andesite. M3 has many voids fringed with euhedral quartz grains. Because the shape and size of these voids are analogous to those of the phenocrysts in the protolith andesite, they are considered to be relicts of phenocrysts (plagioclase and pyroxene) that dissolved into hydrothermal fluids. Euhedral quartz grains are the consequence of crystallization from the hydrothermal fluids in the spaces vacated by the dissolved phases.

Transformation of the host andesite occurred by hydrothermal silica-rich fluid infiltration. Amorphous silica phase precipitated from the fluid initially replaced the groundmass of andesite. This phase was termed 'residual silica' by Hedenquist et al. (1994), and it later recrystallized to quartz. The phenocrysts of andesite dissolved during the hydrothermal activity and visible voids were left behind. Izawa and Cunningham (1989) studied another Nansatsu-type ore body and allocated the occurrence of the euhedral quartz crystals grown in the open spaces of partially dissolved andesite (abundant in M4 of this study, Fig. 11) to the succeeding stages of hydrothermal alteration. This multistage hydrothermal alteration with decreasing 'center-outward lateral extent' in the Nansatsu District has been supported by several authors (e.g., Arribas 1995 and references therein). Our observations of the quartz crystallographic orientations are conformable to this model of ore deposition. The highly silicified sample from near the hydrothermal fluid source (M4) has larger quartz grains and most of these have $c$-axes plunging at high angles (sub-horizontal basal planes), while in the rock away from the source (M3), few quartz grains have their $\boldsymbol{c}$-axes plunging at high angles.

There is a difference in quartz $\boldsymbol{c}$-axis orientations between the two undeformed rock samples. The abundance of quartz grains with highly plunging $\boldsymbol{c}$-axes are provably related to the silicification processes in the earlier stages of hydrothermal alteration. A possibility for the particular crystallization style of quartz grains growing free of any physical restraint is the movement path of the silica-rich fluid away from the source. Closer to the source (center of ore body) the fluid course was near vertical and so the grains with vertical $\boldsymbol{c}$-axes outgrew the grains with other orientations. Away from the source, the fluid path was directed laterally and so the grains with horizontal $\boldsymbol{c}$-axis prevail. The fluid trajectory had an effect on the direction of crystal growth leading to the orientations now visible in the Kasuga sections. The results 


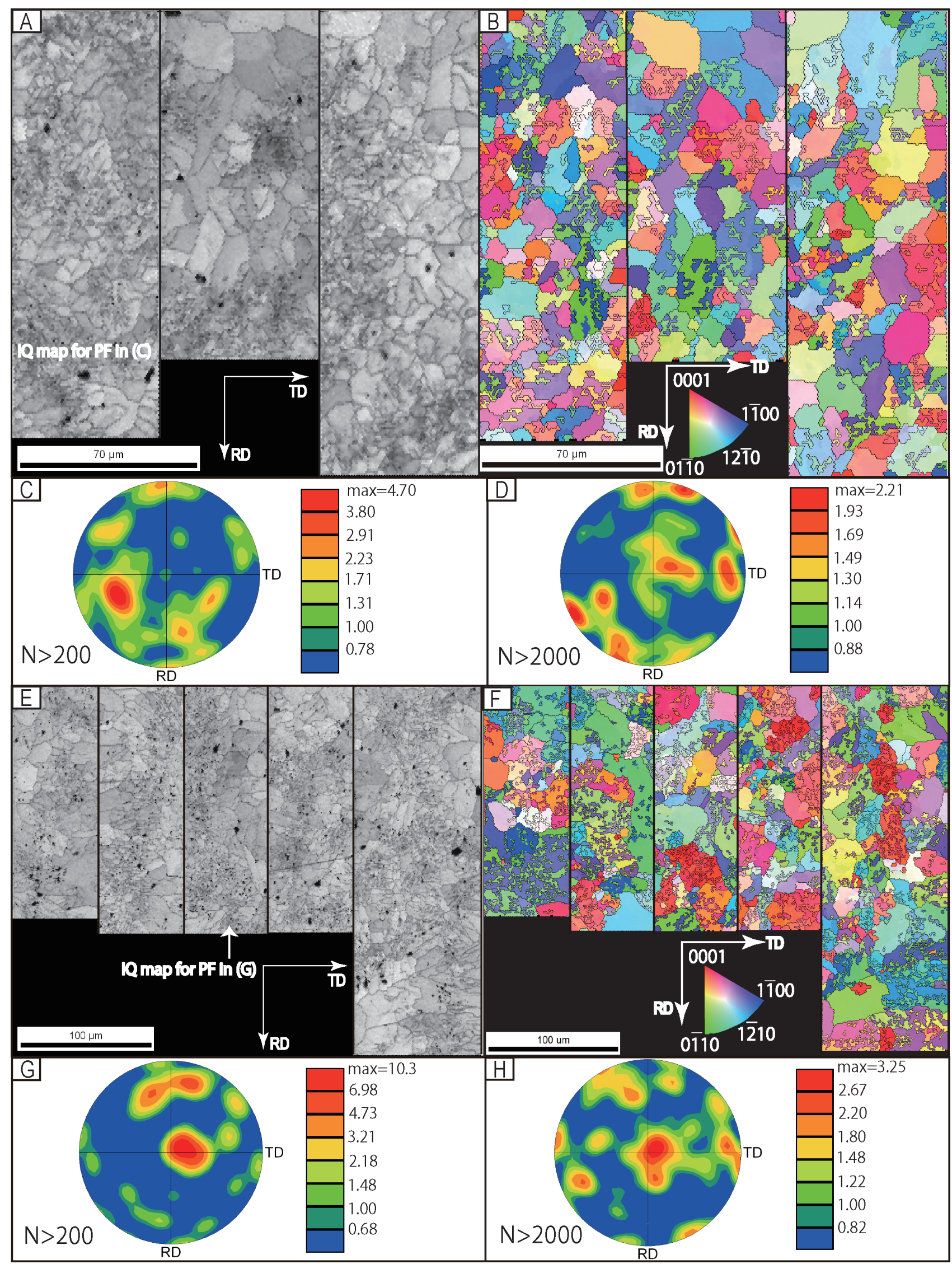



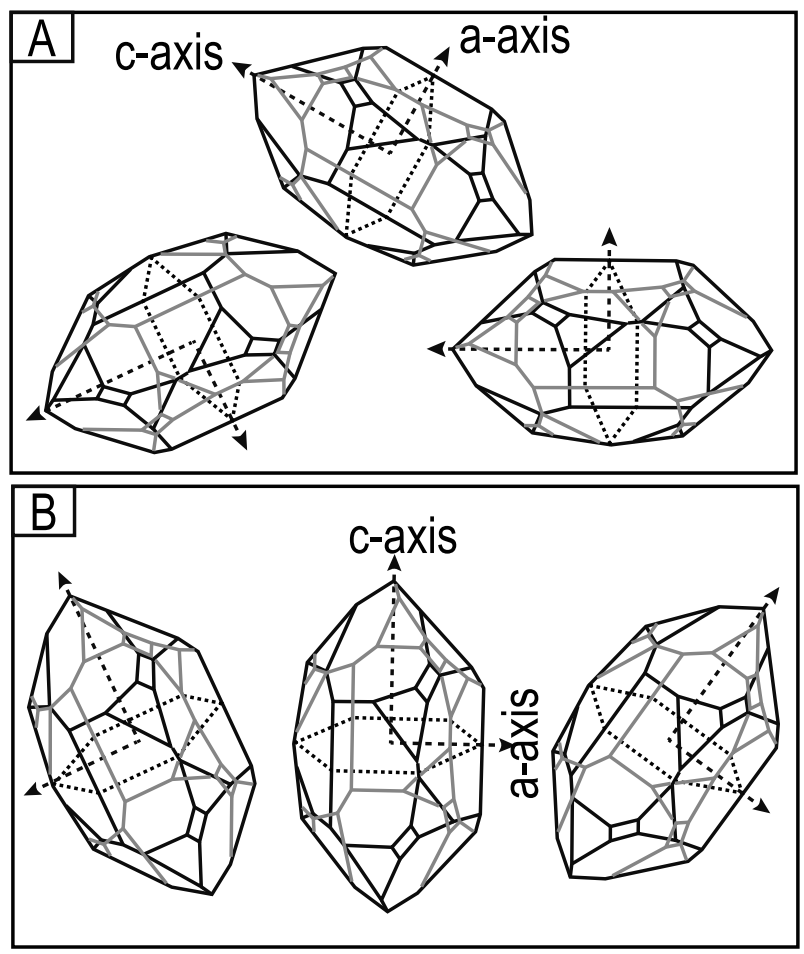

Figure 10. Possible crystallization style of quartz crystals. (A) Responsible for the spread of maxima around the rim of PF's for M3. (B) Responsible for the concentration of $\boldsymbol{c}$-axis maxima in the center of the PF's for M4.

of this study suggest that the distribution patterns of quartz $\boldsymbol{c}$-axis orientations of undeformed quartzose rocks are potentially different even in samples taken from the same body. Therefore, careful evaluation of $\boldsymbol{c}$-axis orientations inherited from initial state of a rock is necessary before we give tectonic interpretations to a quartz $c$-axis fabric for the rocks deformed under low strain regimes.

\section{ACKNOWLEDGMENTS}

We are indebted to E. Narui of Kasuga Mining Co. Ltd. for his approval of our field work in the operating opencast. We thank Y. Oozono of Natural Science Center for Research and Education, Kagoshima University for his help in the EBSD analysis. This paper was improved by the constructive reviews of Jun-ichi Ando and Kazuaki Okamoto. Careful editorial handling by Koichiro Fujimo-
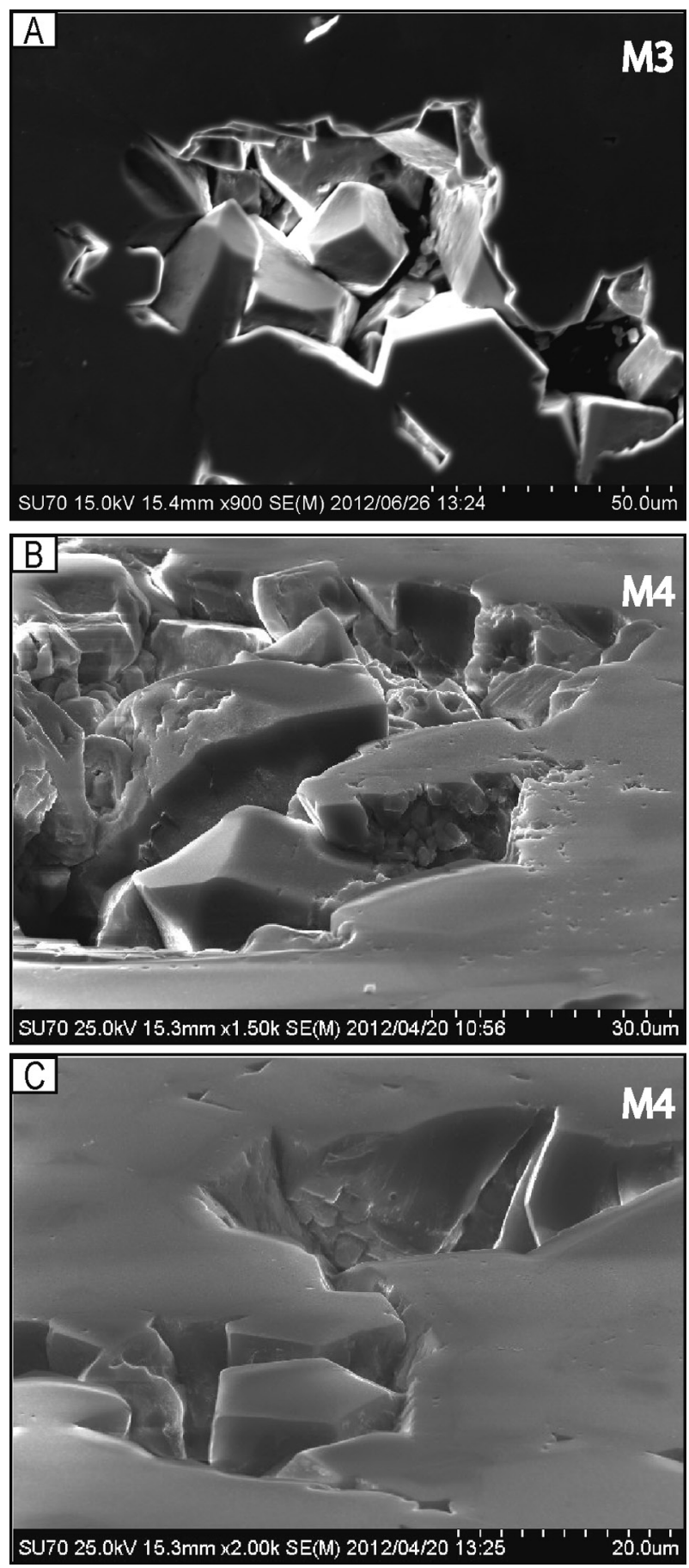

Figure 11. SEM images of the silicified rock samples. Euhedral quartz crystals visible within very fine-grained silica in both less-silicified (A) and highly-silicified (B) and (C) rock thin sections.

Figure 9. OIM analysis output of samples M3 (A, B, C, D) and M4 (E, F, G, H). RD faces the North. (A) Three representative gray-scale IQ maps from area scans at 7 locations in total. Areas with highest quality are white, while those with poorest are black. (B) Three representative colour coded IPF maps. A colour-coded inverse pole figure as colour index is shown at the bottom. Grain boundaries indicated by thin black lines occur whenever the orientation difference between adjacent points is more than $10^{\circ}$. (C) Pole figure (intensity plot of equal-area lower hemisphere projection of the quartz $c$-axes) drawn from orientation data of a representative scan (indicated in A). ' $N$ ' indicates the approximate number of grains used in calculating the texture. Scale on the right. (D) Pole figure drawn from combined $c$-axis orientation data for 7 scans. (E) Gray-scale IQ maps from area scans at 5 locations. (F) IPF maps of the 5 area scans. (G) Pole figure drawn from orientation data of a representative scan (indicated in E). (H) Pole figure drawn from combined $c$-axis orientation data for 5 scans. 
to is greatly appreciated. The study was supported partly by the JSPS Grant-in-Aid for Scientific Research (KAKENHI: 22540472).

\section{REFERENCES}

Arribas, A.Jr. (1995) Characteristics of high-sulfidation epithermal deposits, and their relation to magmatic fluid. In Magmas, Fluids, and Ore Deposits (Thompson, J.F.H. Ed.). Mineralogical Association of Canada, Short Course, 23, 419-454.

Cooke, D.R., Hollings, P. and Walshe, J.L. (2005) Giant Porphyry Deposits: Characteristics, distribution, and tectonic controls on economic geology. Economic Geology, 100, 801-818.

Den Brok, S.W.J. and Spiers, C.J. (1991) Experimental evidence for water weakening of quartzite by microcracking plus solution-precipitation creep. Journal of the Geological Society, London, 148, 521-548.

Gonçalves, C.P. de Castro and Lagoeiro, L.E. (2009) U-stage and EBSD technique as complementary methods. Revista Brasileira de Geociência, 39, 112-128.

Hedenquist, J.W., Matsuhisa, Y., Izawa, E., White, N.C., Giggenbach, W.F. and Aoki, M. (1994) Geology, geochemistry, and origin of high sulfidation $\mathrm{Cu}-\mathrm{Au}$ mineralization in the Nansatsu district, Japan. Economic Geology, 89, 1-30.

Hippertt, J.F. (1994) Microstructures and $c$-axis fabrics indicative of quartz dissolution in sheared quartzites and phyllonites. Tectonophysics, 229, 141-163.

Izawa, E. and Cunningham, C.G. (1989) Hydrothermal breccia pipes and gold mineralization in the Iwashita Orebody, Iwato Deposit, Kyushu, Japan. Economic Geology, 84, 715-724.

Kawanabe, Y., Sakaguchi, K., Saito, M., Komazawa, M. and Yamazaki, T. (2004) Geological Map of Japan, 1:200,000, Kaimondake, Geological Survey of Japan, AIST, Ibaraki (in Japanese with English abstract).

Kodama, K., Tashiro, H. and Takeuchi, T. (1995) Quaternary counterclockwise rotation of south Kyushu, southwest Japan. Geology, 23, 823-826.

Passchier, C.W. and Trouw, R.A.J. (1996) Microtectonics. pp. 289, Springer, Berlin.
Prior, D.J., Boyle, A.P., Brenker, F., Cheadle, M.C., Day, A., Lopez, G., Peruzzo, L., Potts, G.J., Reddy, S., Spiess, R., Timms, N.E., Trimby, P., Wheeler, J. and Zetterström, L. (1999) The application of electron backscatter diffraction and orientation contrast imaging in the SEM to textural problems in rocks. American Mineralogist, 84, 1741-1759.

Prior, D.J., Wheeler, J., Peruzzo, L., Spiess, R. and Storey, C. (2002) Some garnet microstructures: an illustration of the potential orientation maps and misorientation analysis in microstructural studies. Journal of Structural Geology, 24, 9991011.

Takeda, T., Shimada, N. and Ueno, H. (2001) Paleomagnetic constraints on the Nansatsu-type gold deposits in southern Kyushu, Japan. Resource Geology, 51, 239-248.

Trepmann, C., Lenze, A. and Stockhert, B. (2010) Static recrystallization of vein quartz pebbles in a high-pressure-low-temperature metamorphic conglomerate. Journal of Structural Geology, 32, 202-215.

Urashima, Y. (1975) Gold-silver deposits in Japan. In: Gold-Silver Ores in Japan, No. 1, 1-42, Journal of the Mining and Metallurgical Institute of Japan (in Japanese).

Urashima, Y., Izawa, E. and Hedenquist, J.W. (1987) NansatsuType Gold Deposits in the Makurazaki District. Urashima, Y. (ed.), Guidebook 2, Gold Deposits and Geothermal Fields in Kyushu, Society of Mining Geologists of Japan, 13-22.

Uto, K., Sakaguchi, K., Teraoka, Y., Okumura and K., Komazawa, M. (1997) Geological map of Japan, 1:200,000, Kagoshima. Geological Survey of Japan.

Vernooij, M.G.C., Brok, B.D. and Kunze, K. (2006) Development of crystallographic preferred orientations by nucleation and growth of new grains in experimentally deformed quartz single crystals. Tectonophysics, 427, 35-53.

Watanabe, Y. (2005) Late Cenozoic evolution of epithermal gold metallogenic provinces in Kyushu, Japan. Mineralium Deposita, 40, 307-327.

Manuscript received January 18, 2013

Manuscript accepted July 16, 2013

Published online September 19, 2013

Manuscript handled by Koichiro Fujimoto 